\title{
Language laterality assessed by unilateral ECT and dichotic monitoring
}

\author{
G I A GEFFEN, ELIZABETH TRA UB, A N INEKE STIERMAN
}

From the Psychology Discipline, School of Social Sciences, The Flinders University of South Australia, Adelaide, Australia

SUM MARY A dichotic monitoring test for the lateralisation of speech dominance was compared with testing for dysphasia after unilateral electroconvulsive therapy to each side of the head in 31 patients, and the intracarotid amylobarbitone test in four epileptic patients. Twenty-eight patients shown to be left speech dominant also showed right ear advantages in the dichotic test. Four of the five right speech dominant patients showed left ear advantages. Two patients with bilateral speech representation showed nonsignificant ear asymmetries. The noninvasive dichotic monitoring task is quick and simple and produces large mean ear advantages (14 to $25 \%$ ) in normal subjects as well as patients.

The incidence of speech representation in the right hemisphere has been assessed by examining whether patients with unilateral cerebral lesions exhibit dysphasia (Zangwill, 1967). However, in patients requiring cerebral neurosurgery or unilateral electroconvulsive therapy (ECT), it is important to predict language lateralisation. A widely used method for this purpose is the occurrence of dysphasia after unilateral injection of sodium amylobarbitone into the carotid artery (Wada and Rasmussen, 1960; Branch et al., 1964). This test was found to predict with $95 \%$ accuracy the side of speech production, assessed by whether patients showed dysphasia after removal of the amylobarbitone-predicted nondominant temporal lobe (Davis and Wada, 1977). However, the side of speech perception and comprehension, as opposed to speech production, cannot be adequately tested with the amylobarbitone technique since the unilateral depressant action of the drug is too shortlived. The degree of dysphasia during the recovery period after successive unilateral electroconvulsive treatments to the left and right sides of the head has been used to determine language laterality in depressed patients (Warrington and Pratt, 1973; Annett et al., 1974). This method has been used when ECT was required for therapy,

Address for reprint requests: Dr G. Geffen, School of Social Sciences, The Flinders University of South Australia, Bedford Park, 5042, Australia.

Accepted 31 October 1977 and its accuracy has not been evaluated using other measures of laterality.

Dichotic recall has not been used clinically to determine which hemisphere controls speech, although the right ear advantage (REA) obtained with dichotic recall has been interpreted in terms of left hemisphere superiority for processing speech signals (Kimura, 1961a, b; StuddertKennedy and Shankweiler, 1970). Kimura (1961b) and Milner (1962) reported the dichotic recall performance of 120 patients. Nineteen left handed patients had received the sodium amylobarbitone test. Ten left speech dominant (LSD) patients showed a mean REA of $5 \%$, whereas nine right speech dominant (RSD) patients had a mean left ear advantage (LEA) of $6 \%$. The 96 right handed patients were presumed to be LSD and were not given the invasive sodium amylobarbitone test. Thus the validity of dichotic listening for predicting speech dominance has not been adequately tested. The existence of unilateral temporal lobe epileptogenic foci in the patient sample of Kimura (1961b) and Milner (1962) might have produced atypical language lateralisation and affected the direction and magnitude of ear differences. Moreover, the ear advantage using dichotic recall is too small to be reliable.

A dichotic monitoring task involving a manual response to target word detection has advantages over dichotic recall. A $20 \%$ REA was found to be constant between children aged 5, 7, and 11 years 
(Geffen, 1976), as opposed to the 5\% REA found in dichotic recall (Kimura, 1963). Response times (RT) were faster to right than left ear target words by $72 \mathrm{~ms}$ and a signal detection analysis showed that response bias did not contribute to the REA. This technique determines perceptual asymmetry in response to speech signals without the confounding effects of memory and speech production factors. The present study used dichotic monitoring in patients whose language laterality was established by unilateral ECT.

\section{Methods}

Thirty-one patients (19 female, 12 male) between 17 and 64 years old receiving ECT for the treatment of depression either for the first time, or on the first course of treatments within six months, were tested. Four epileptic patients with either left or right temporal lobe foci (three) or unspecified foci (one) between 11 and 27 years who received the sodium amylobarbitone test were also included. The ECT sample contained no patients with organic brain disorder. A group of 31 (15 female and 16 male) normal, right handed subjects (age range 18 to 49 years) received the dichotic monitoring test for the purposes of comparison with the patient sample.

Handedness was assessed by the Annett (1970) questionnaire. On the basis of responses to the six primary questions (items 1-4, 10, and 11) 25 patients were right handed, four were mixed left handers, and two were strong left handers. In testing for dysphasia after ECT, the four questions used by Pratt and Warrington (1972) were followed by five simpler questions-for example, "What do you wear on your feet?" These were included in case the four initial questions were beyond the patient's comprehension. Only the first four questions were scored in all but three patients whose scores were obtained on questions 5-8.

The dichotic monitoring task was prepared by recording five lists of 68 different dichotic monosyllabic word pairs on channels 1 and 2 of a Sony TC 854 four channel tape recorder at a rate of one pair per $750 \mathrm{~ms}$. The mean onset asynchrony between word pairs was $32 \mathrm{~ms}$ (SD $13 \mathrm{~ms}$ ), and they were played at a mean intensity of $70 \mathrm{~dB} \pm 4 \mathrm{~dB}, B$ scale, per channel, as measured by a Philips PM 6400 sound level meter over a pair of matched TDH-39 headphones in Maico aural domes. The target item was the word DOG which occurred eight times on each channel in each list. There were also eight noise words per channel, which shared two phonemes in common with the target word-for example, DIG, LOG. The other 52 words on each channel were dissimilar from the target word on all three phonemes. Target, noise, and dissimilar words were randomised with the constraints that target and noise words did not occur simultaneously on both channels successively within or between channels, or on the first or last four pairs of the list.

TESTING FOR DYSPHASIA AFTER UNILATERAL ECT

On two successive unilateral treatments, patients were tested on the naming-to-description task according to the procedure outlined by Pratt and Warrington (1972). Electrode placement was temporoparietal. The first treatment was given on the left side of the head in 15 patients and on the right side in 16 patients. The mean voltage was $110 \mathrm{~V}$ for a mean duration of 1.29 seconds. Within each patient, these were constant between the two treatments. The premedication, anaesthetic, and muscle relaxant drugs did not differ between treatments, neither were there changes in administration of drug therapy between the treatments. A gross measure of seizure duration was timed by stopwatch from the time the psychiatrist pressed the button on the ECT machine (Camelec Electronic Model CTU-72) till the tonic phase ceased. All observed seizures were bilateral and did not differ in duration between treatments. The actual time was noted when ECT was given, when the patient gave his or her name correctly, when the fourth question was completed, and when the ninth question was completed. Each question was repeated once if necessary.

\section{DICHOTIC MONITORING}

This was tested in the morning before the first ECT treatment or during the preceding two days. A $1.0 \mathrm{kHz}$ tone lasting $5 \mathrm{~s}$ was presented to the two ears at an equal intensity $(65 \mathrm{~dB})$. This prerecorded tone would be heard centrally if hearing was equally good in either ear. Patients were asked to judge the location of the tone with matched and mismatched volume settings on channels 1 and 2. Monaural target detection rates were then measured on two lists to determine whether hearing was equally good in the left and right ears for this particular speech perception task. No patients included in this sample showed ear differences on the monaural task. Two patients, who failed to locate a tone of matched volumes centrally and had larger monaural scores for one ear, were not tested further. The patient's task was to press a button with the forefinger whenever the word DOG was detected on either ear. A practice list of 68 dichotic word pairs was given, with one hand responding for the first 34 pairs and the other hand 
responding for the second half of the list. Visual fixation was maintained on a spot in the centre of the response panel during list presentation. The four lists were then given with the headphones reversed after each list to control for channel differences. Each hand responded on two lists counterbalanced in RLLR (14 patients) or LRRL (17 patients) order. This gave a maximum of 16 targets per ear-hand combination and 32 targets per ear. The entire session lasted about 15 minutes. The normal subjects and epileptic patients were tested in the same way. The results of the sodium amylobarbitone test were unknown at the time of dichotic testing.

On channel 3 of the dichotic tape were tones which coincided with the onset of the target and noise words. The patient's button pressing response produced an $8 \mathrm{kHz}, 300 \mathrm{~ms}$ tone which was recorded on channel 4 of that tape. Channels 3 and 4 were subsequently analysed using a PDP 11-10 computer to obtain correct detections, errors, and their reaction times. The scoring was carried out after the two ECT treatments were completed so that any ear differences were not known at the time of testing for dysphasia after unilateral ECT.

\section{Results}

The dichotic monitoring performance of the normal group and ECT patient sample is shown in Fig. 1. Analyses of variance (normal versus patients (2) Xear (2) $\times$ hand $(2) \times$ subjects $(62)$ ) were carried out on the proportion of target words responded to (hit rate), errors (false positive rate), and RT to target words.

Hit rates were higher for the normal subjects than for the patients, $F(1,60)=8.91, P<0.01$ ( $\bar{X}$ difference $=7 \%$ ), and higher for the right than the left ear, $\mathrm{F}(1,60)=79.46, \mathrm{P}<0.001$ ( $\bar{X}$ difference $=19 \%$ ). Only three normal subjects and four patients showed an LEA. The main effect of responding hand and the two- and threeway interactions were not significant.

Target words were responded to faster by the normal than the patient group, $F(1,60)=7.03$, $\mathbf{P}<0.05$ ( $\bar{X}$ difference $=55 \mathrm{~ms}$ ). Right ear targets received faster responses than those in the left ear, $\mathrm{F}(1,60)=35.67, \mathrm{P}<0.001$ ( $\overline{\mathrm{X}}$ difference $=55 \mathrm{~ms}$ ). Neither the main effect of hand, nor any of the two- or threeway interactions were significant.

There were slightly more $(3 \%)$ false positive responses to noise words on the right than left ear, $\mathrm{F}(1,60)=11.85, \mathrm{P}<0.01$. Only 14 normal subjects and 16 patients responded to more noise words on the right ear, nine people in each group had equal false responses in the two ears, while eight normal subjects and six patients showed a greater number of false positive responses to left ear noise words. In the analysis of false positives the patients did not differ from the normal group, and there were also no significant differences for hand, nor were any of the interactions significant.

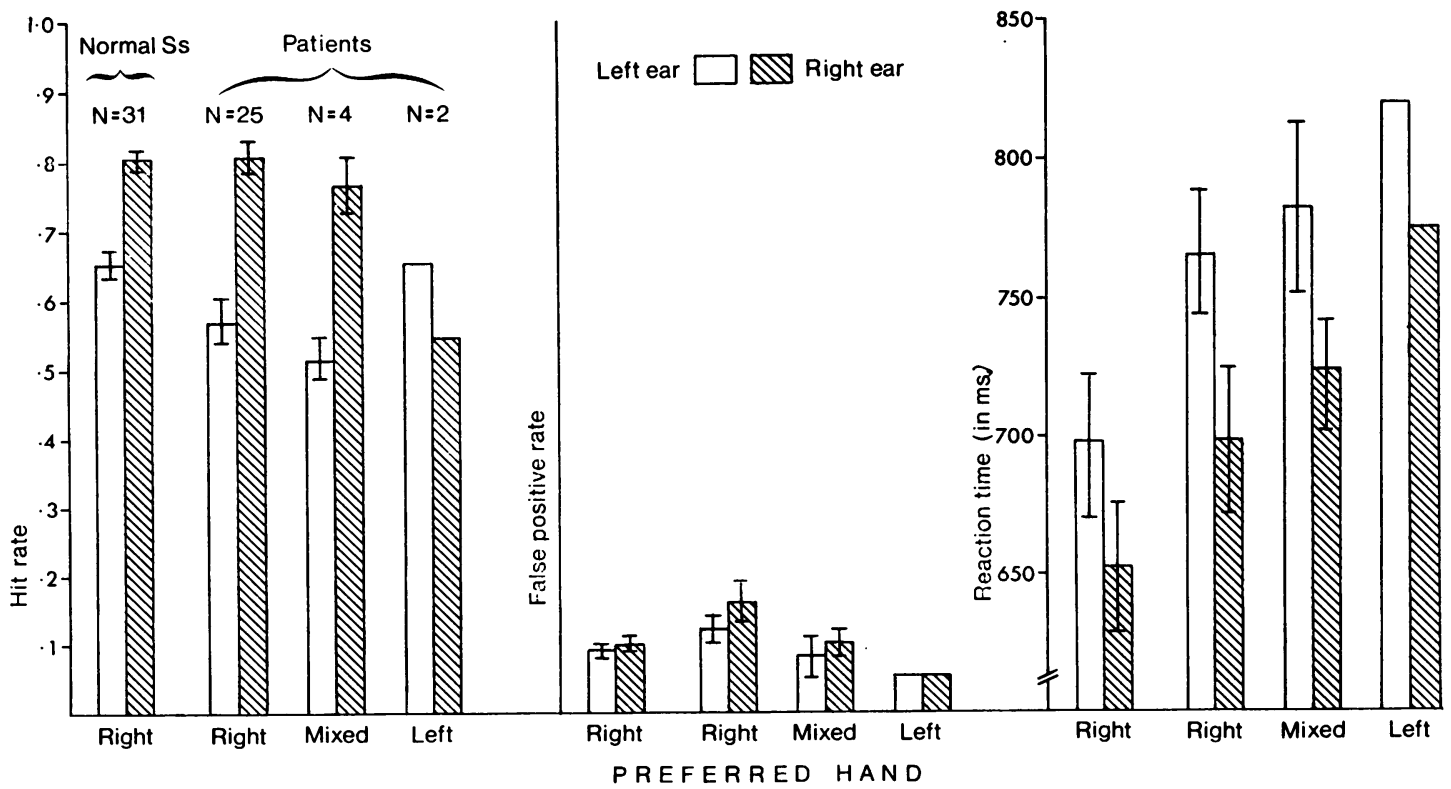

Fig. 1 Mean dichotic monitoring performance of 31 normal right handed subjects and 31 ECT patients. 
In summary, both the normal and patient groups had a similar REA in terms of hit rate and $\mathrm{RT}$, although the patients were slower to respond and missed more targets. Since the ear difference found for false positive responses was smaller and inconsistent, the REA for hit rates cannot be attributed to response bias.

In the ECT sample, the four mixed left handers had REAs similar in magnitude to the right handers, and the two strong left handers showed LEAs one large $(14 \%)$ and one small $(8 \%)$.

DYSPHASIA AFTER UNILATERAL ECT

After left sided ECT fewer questions were correctly answered than after right sided ECT (Fig. 2).

Twenty-six patients were LSD. Only three patients correctly answered more questions after left than right sided treatment and were, therefore, RSD. Two patients gave correct answers to the four critical questions after each ECT treatment. Either their speech functions were bilaterally represented, or this procedure failed to locate the speech hemisphere. The times between reception of ECT and patients answering own name did not differ between side of treatment nor first versus second treatment, using the Wilcoxon paired-replicates test, confirming the result of Annett et al. (1974).
PREDICTIVE VALIDITY OF THE EAR ADVANTAGE

Table 1 relates speech dominance to the ear advantages for the ECT and epileptic samples combined. With one exception (patient 3, see appendix) the ear contralateral to the dominant hemisphere showed an advantage during dichotic monitoring (Fisher's exact $\mathrm{P}=0.0073$ ). In the ECT sample, of the three RSD patients, two showed LEAs and one showed an REA. The value of phi for the ECT sample on its own was +0.80 (Fisher's exact $P=0.0014)$. The phi coefficient for handedness in Table 1 is given for comparison only. If all right handed patients were assumed to have speech in their left hemispheres, two out of $24(8 \%)$ would have been misclassified. The nine non-right handers could not have been predicted by their handedness, since six had left and three had right sided speech representation. The handedness prediction would thus yield an uncertainty or inaccuracy of 11 out of 33 or $33.3 \%$.

The significance of each patient's ear difference was analysed by computing phi coefficients (Kuhn, 1973) on individual target detection rates. The null hypothesis in this test is that the hit rate will not differ significantly between the ears. Table 2 shows the significance of the left or right ear advantage for patients with left, right, or bilateral

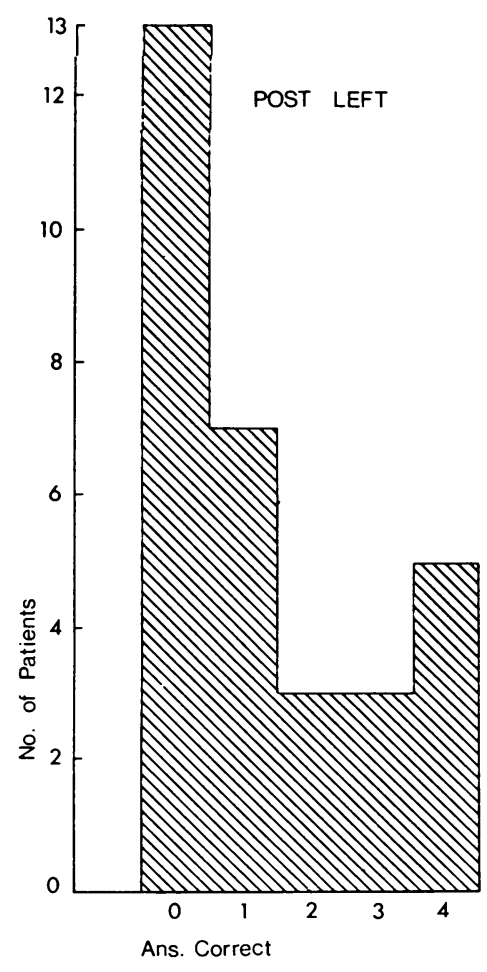

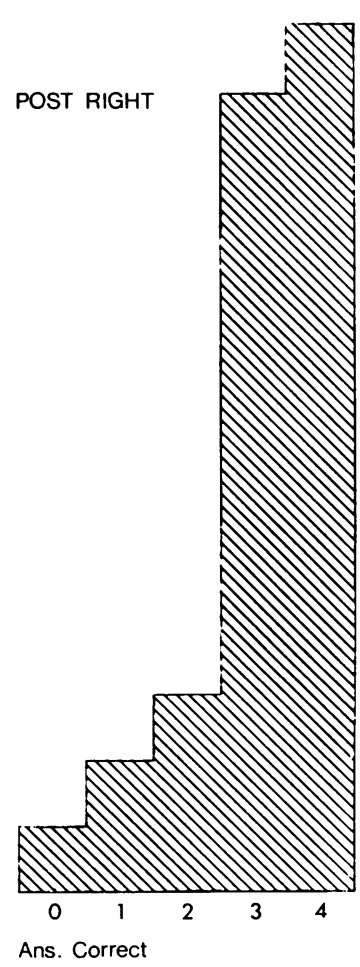

Fig. 2 Number of patients correctly answering questions after left and right sided ECT. 
Table 1 Thirty-three patients classified in terms of language laterality, handedness, and ear advantage. Two patients with presumed bilateral representation of speech are omitted. The phi coefficients indicate the predictive validity of dichotic monitoring compared to handedness

\begin{tabular}{llcll}
\hline & \multicolumn{4}{c}{ Speech hemisphere } \\
\cline { 3 - 5 } & & Left & Right & Phi \\
\hline Ear & Left & 0 & 4 & 0.88 \\
advantage & Right & 28 & 1 & \\
Preferred & Left & 6 & 3 & 0.30 \\
hand & Right & 22 & 2 & \\
\hline
\end{tabular}

Table 2 Significance level of phi coefficients on hit rates in dichotic monitoring for 35 patients

\begin{tabular}{|c|c|c|c|c|c|c|}
\hline \multirow{3}{*}{$\begin{array}{l}\text { Significance } \\
\text { level }\end{array}$} & \multicolumn{6}{|c|}{ Speech hemisphere } \\
\hline & \multicolumn{2}{|l|}{ Left } & \multicolumn{2}{|c|}{ Right } & \multicolumn{2}{|l|}{ Both } \\
\hline & $L E A$ & $R E A$ & $L E A$ & $R E A$ & $L E A$ & $R E A$ \\
\hline $\begin{array}{l}0.01 \\
0.05 \\
0.10^{*} \\
\text { NS }\end{array}$ & $\begin{array}{l}- \\
- \\
-\end{array}$ & $\begin{array}{c}11 \\
10 \\
3 \\
4 \dagger\end{array}$ & $\begin{array}{r}1 \\
2 \\
1 \\
-\end{array}$ & $\frac{1}{-}$ & $\frac{-}{\overline{2}}$ & $\overline{-}$ \\
\hline Total & \multicolumn{2}{|c|}{28} & \multicolumn{2}{|r|}{5} & \multicolumn{2}{|c|}{2} \\
\hline
\end{tabular}

*Ear difference of $14 \%$, significant at $\mathrm{P}<0.10$.

$\dagger R T$ shows REA of $125,83,67$, and $32 \mathrm{~ms}$.

‡RT shows REA of 12 and $9 \mathrm{~ms}$.

speech representation. The 28 patients with left sided speech either had large (at least 14\%) REAs in terms of hit rate differences, or responded substantially faster to right rather than left ear target words. Four of the five RSD patients showed significant LEAs. The one exception showed a significant REA. The two patients who were assumed to have bilateral speech representation had nonsignificant LEAs but slightly faster responses to right than to left ear target words.

\section{Discussion}

The ear contralateral to the dominant hemisphere for speech, as determined by unilateral ECT or the sodium amylobarbitone test, was found to be superior in terms of hit rate or reaction time or both during dichotic monitoring performance. Where no evidence for hemispheric asymmetry of speech function was found, no significant ear differences were found (two patients). The dichotic monitoring performance of the depressed patients was similar to that of normal adults. The prediction of speech dominance by the dichotic monitoring test was very accurate in this limited sample. Only one patient out of 35 was misclassified by this test, an accuracy of at least $97 \%$. This compares well with the results of the sodium amylobarbitone test which is between $95 \%$ (Davis and Wada, 1977) and $98 \%$ accurate (Branch et al., 1964).

As expected, handedness was not directly related to speech dominance (Heilman et al., 1973, 1974). Three of the nine $(33 \%)$ non-right handed patients were RSD for speech (Table 1). This proportion accords well with the studies of the effects of lesions (Hécaen and Ajuriaguerra, 1964), electrostimulation of the exposed cortex (Penfield and Roberts, 1959), the carotid amylobarbitone test (Branch et al., 1964), and dysphasia after unilateral ECT (Warrington and Pratt, 1973). Two of the 24 $(8 \%)$ right handed patients had speech represented in their right hemisphere. This proportion is smaller than the four out of $32(12.5 \%)$ and three out of $24(12 \%)$ incidence of "crossed dominance" found in right handers by Fleminger et al. (1970) and Annett et al. (1974), but larger than the one in $55(1.8 \%)$ found by Warrington and Pratt (1973). The sodium amylobarbitone technique yielded an incidence of five out of $48(10 \%)$ (Branch et al., 1964), and two out of 14 (14\%) (Davis and Wada, 1977), giving $11 \%$ of RSD right handers overall. Combining the series of both unilateral ECT and sodium amylobarbitone studies gives 17 out of $195(8.7 \%)$ of right handers with greater right than left hemisphere speech representation. Since the probability of error in determining language laterality is smaller in a right handed than in a left handed person, it is frequently assumed to be unnecessary to investigate speech representation in right handed patients. However, only 3 to $30 \%$ of the population is nonright handed (Annett, 1970). Therefore, an incorrect decision of side of language dominance would be made for a greater number of right than left handed individuals in a representative sample. It is clearly important to determine language lateralisation in both left and right handed patients requiring neurosurgery or ECT.

A noninvasive test of speech lateralisation which relies on spectral analysis of evoked potentials to flash and click stimuli has been reported (Davis and Wada, 1977). It was claimed to predict the speech dominant hemisphere with a $90 \%$ accuracy. However, this level of accuracy was obtained only when both spectral analysis and handedness were taken into account. With spectral analysis alone, four out of $22(18 \%)$ misclassifications resulted. In contrast, the dichotic monitoring test was $97 \%$ accurate on its own. Furthermore, it is a recognised test of speech perception (Studdert-Kennedy and Shankweiler, 1970; Springer, 1971), with more obvious face validity than evoked potentials to such nonspeech signals as clicks and flashes. 
In conclusion, the dichotic monitoring task allows a noninvasive determination of speech dominance. The accuracy of prediction is superior to one based on handedness or spectral analysis. Unlike the sodium amylobarbitone technique, dichotic monitoring is a test of speech perception rather than of speech production. This has implications for neurosurgical decisions, since loss of speech perception, which is essential for comprehension and communication, is more incapacitating than loss of speech production. We are currently testing the reliability of the dichotic monitoring technique.

This research was supported by a grant to Dr Gina Geffen from the National Health and Medical Research Council of Australia. The authors are grateful for the co-operation of Glenside, Hillcrest, and Enfield Hospitals in Adelaide.

\section{References}

Annett, M. (1970). A classification of hand preference by association analysis. British Journal of Psychology, 61, 303-321.

Annett, M., Hudson, P. T. W., and Turner, A. (1974). Effects of right and left unilateral ECT on naming and visual discrimination analysed in relation to handedness. British Journal of Psychiatry, 124, 260-264.

Branch. C., Milner, B., and Rasmussen, T. (1964). Intracarotid sodium amytal for the lateralization of cerebral speech dominance. Journal of Neurosurgery, 21, 399-405.

Davis, A. E., and Wada, J. A. (1977). Lateralisation of speech dominance by spectral analysis of evoked potentials. Journal of Neurology, Neurosurgery, and Psychiatry, 40, 1-4.

Fleminger, J. J., Horne, D. J. deL., and Nott, P. N. (1970). Unilateral electroconvulsive therapy and cerebral dominance: effect of left- and right-sided elestrode placement on verbal memory. Journal of Neurology, Neurosurgery, and Psychiatry. 33, 408411.

Geffen, G. (1976). Development of hemispheric specialization for speech perception. Cortex, 12, 337-346.
Hécaen. H., and Ajuriaguerra, J. (1964). Lefthandedness, Manual Superiority and Cerebral Dominance. Grune and Stratton: New York.

Heilman, K. M., Coyle, J. M., Gonyea, E. F., and Geschwind, N. (1973). Apraxia and agraphia in a left-hander. Brain, 96, 21-28.

Heilman, K. M., Coyle, J. M., Gonyea. E. F., and Geschwind, N. (1974). Apraxia and agraphia in a right-hander. Cortex, 10, 284-288.

Kimura, D. (1961a). Some effects of temporal-lobe damage on auditory perception. Canadian Journal of Psychology, 15, 156-165.

Kimura, D. (1961b). Cerebral dominance and the perception of verbal stimuli. Canadian Journal of Psychology, 15, 166-171.

Kimura, D. (1963). Speech lateralization in young children as determined by an auditory test. Journal of Comparative and Physiological Psychology, 56, 899-902.

Kuhn, G. M. (1973). The phi coefficient as an index of ear differences in dichotic listening. Cortex, 9, 447-457.

Milner, B. (1962). Laterality effects in audition. In Interhemispheric Relations and Cerebral Dominance, pp. 177-195. Edited by V. B. Mountcastle. Johns Hopkins Press: Baltimore.

Penfield, W., and Roberts, L. (1959). Speech and Brain Mechanisms. Princeton University Press: Princeton, New Jersey.

Pratt, R. T. C., and Warrington, E. K. (1972). The assessment of cerebral dominance with unilateral ECT. British Journal of Psychiatry, 121, 327-328.

Springer, S. (1971). Ear asymmetry in a dichotic detection task. Perception and Psychophysics, 10, 239241.

Studdert-Kennedy. M., and Shankweiler, D. (1970). Hemispheric specialization for speech perception. Journal of the Acoustical Society of America, 48, 579-594.

Wada, J., and Rasmussen, T. (1960). Intracarotid injection of sodium amytal for the lateralization of cerebral speech dominance. Experimental and clinical observations. Journal of Neurosurgery, 17, 266-282.

Warrington, E. K., and Pratt, R. T. C. (1973), Language laterality in left-handers assessed by unilateral ECT. Neuropsychologia, 11, 423-428.

Zangwill, O. L. (1967). Speech and the minor hemisphere. Acta Neurologica et Psychiatrica Belgica, 67, 1013-1020. 
Group 1 Data on ECT sample, right handers

\begin{tabular}{|c|c|c|c|c|c|c|c|c|}
\hline \multirow{3}{*}{$\begin{array}{l}\text { Patient } \\
\text { number }\end{array}$} & \multirow[t]{3}{*}{$\operatorname{Sex}$} & \multirow[t]{3}{*}{$\operatorname{Age}(y r)$} & \multirow{3}{*}{\multicolumn{2}{|c|}{$\begin{array}{l}\text { Questions correct after } \\
\text { treatment to left }(L) \text { and } \\
\text { right }(R) \text { side of head } \\
L\end{array}$}} & \multirow{3}{*}{$\begin{array}{l}\text { Language } \\
\text { laterality } \\
\text { left }(L), \text { right } \\
(R), \text { bilateral } \\
(B)\end{array}$} & \multicolumn{3}{|c|}{ Dichotic monitoring } \\
\hline & & & & & & \multicolumn{2}{|c|}{ Hit rate $(\%)$} & \multirow[b]{2}{*}{$\begin{array}{l}\text { Difference } \\
R-L\end{array}$} \\
\hline & & & & & & $\begin{array}{l}\text { Left } \\
\text { ear }\end{array}$ & $\begin{array}{l}\text { Right } \\
\text { ear }\end{array}$ & \\
\hline 1 & $\mathbf{F}$ & 28 & 1 & 3 & $\mathbf{L}$ & 39 & 100 & 61 \\
\hline 2 & $\mathbf{F}$ & 58 & 1 & 3 & $\mathbf{L}$ & 27 & 75 & 48 \\
\hline 3 & $\mathbf{M}$ & 56 & 4 & 3 & $\mathbf{R}$ & 47 & 94 & 47 \\
\hline 4 & $\mathbf{M}$ & 29 & 2 & 3 & $\mathbf{L}$ & 50 & 94 & 44 \\
\hline 5 & $\mathbf{F}$ & 50 & 0 & 4 & $\overline{\mathbf{L}}$ & 42 & 85 & 43 \\
\hline 6 & $\mathbf{F}$ & 21 & 0 & 4 & L & 31 & 73 & 42 \\
\hline 7 & $\mathbf{M}$ & 35 & 0 & $1^{*}$ & L. & 47 & 88 & 41 \\
\hline 8 & $\mathbf{F}$ & 47 & 2 & 3 & L & 28 & 67 & 39 \\
\hline 9 & $\mathbf{F}$ & 54 & 3 & $4^{*}$ & $\mathbf{L}$ & 56 & 91 & 35 \\
\hline 10 & $\mathbf{F}$ & 48 & 0 & 2 & $\mathbf{L}$ & 30 & 62 & 32 \\
\hline 11 & $\mathbf{M}$ & 21 & 0 & 3 & L & 30 & 59 & 29 \\
\hline 12 & $\mathbf{M}$ & 50 & 3 & $4^{*}$ & $\mathbf{L}$ & 67 & 94 & 27 \\
\hline 13 & $\mathbf{M}$ & 48 & 1 & 4 & L & 47 & 73 & 26 \\
\hline 14 & $\mathbf{F}$ & 64 & 0 & 3 & $\mathbf{L}$ & 52 & 75 & 23 \\
\hline 15 & $\mathbf{F}$ & 52 & 0 & 4 & $\overline{\mathbf{L}}$ & 61 & 81 & 20 \\
\hline 16 & $\mathbf{M}$ & 34 & 0 & 2 & $\mathbf{L}$ & 61 & 81 & 20 \\
\hline 17 & $\mathbf{F}$ & 53 & 0 & 3 & $\mathbf{L}$ & 55 & 75 & 20 \\
\hline 18 & $\mathbf{M}$ & 37 & 2 & 4 & $\overline{\mathbf{L}}$ & 72 & 91 & 19 \\
\hline 19 & $\mathrm{~F}$ & 21 & 0 & 3 & L & 59 & 76 & 17 \\
\hline 20 & $F$ & 60 & 1 & 3 & L & 78 & 94 & 16 \\
\hline 21 & $F$ & 63 & 0 & 2 & L & 64 & 72 & 8 \\
\hline 22 & $\mathbf{F}$ & 36 & 1 & 4 & $\mathbf{L}$ & 64 & 69 & 5 \\
\hline 23 & $\mathbf{M}$ & 48 & 0 & 4 & $\mathbf{L}$ & 72 & 73 & 1 \\
\hline 24 & $\mathbf{F}$ & 56 & 4 & 4 & B? & 78 & 76 & -2 \\
\hline 25 & $\mathbf{F}$ & 40 & 4 & 3 & $\mathbf{R}$ & 88 & 61 & -27 \\
\hline
\end{tabular}

*Scores for easier questions.

Group 2 Data on ECT sample, mixed left handers

\begin{tabular}{llllllll}
\hline 26 & F & 17 & 1 & 3 & L & 55 & \\
27 & M & 40 & 0 & 1 & L & 42 & 72 \\
28 & M & 47 & 3 & 4 & L & 53 & 70 \\
29 & F & 37 & 3 & 4 & L & 58 & 75 \\
\hline
\end{tabular}

Group 3 Data on ECT sample, strong left handers

\begin{tabular}{llllllll}
\hline 30 & M & 35 & 4 & 0 & R & 78 & -14 \\
31 & F & 18 & 4 & 4 & B ? & 52 & 44 \\
\hline
\end{tabular}

Group 4 Intracarotid amylobarbitone sample (patient 32 mixed left hander, patients 33, 34, and 35 strong left handers)

\begin{tabular}{|c|c|c|c|c|c|c|c|c|}
\hline $\begin{array}{l}32 \\
33 \\
34 \\
35\end{array}$ & $\begin{array}{l}\mathbf{M} \\
\mathbf{M} \\
\mathbf{M} \\
\mathbf{F}\end{array}$ & $\begin{array}{l}16 \\
27 \\
15 \\
11\end{array}$ & $\begin{array}{l}- \\
- \\
-\end{array}$ & $\begin{array}{l}- \\
-\end{array}$ & $\begin{array}{l}\mathbf{L} \\
\mathbf{L} \\
\mathbf{R} \\
\mathbf{R}\end{array}$ & $\begin{array}{l}40 \\
45 \\
55 \\
56\end{array}$ & $\begin{array}{l}49 \\
65 \\
36 \\
26\end{array}$ & $\begin{array}{r}9 \\
20 \\
-29 \\
-30\end{array}$ \\
\hline
\end{tabular}

